\title{
Time to Reperfusion Therapies in ST-Elevation Myocardial Infarction and Identification of Factors Responsible for Delays
}

\author{
Mohammad Azharuddin Malik, MD, DM, FACC ${ }^{1}$, Roez Khan ${ }^{2 *}$
}

${ }^{1}$ Department of Cardiology, Jawahar Lal Nehru Medical College, Aligarh Muslim University, Aligarh, India

${ }^{2}$ Final Year MBBS Student, Jawahar Lal Nehru Medical College, Aligarh Muslim University, Aligarh, India

\begin{abstract}
DOI: $\underline{10.36348 / \mathrm{sjm} .2020 . \mathrm{v} 05 \mathrm{i} 10.001}$
| Received: 22.09.2020 | Accepted: 01.10.2020 | Published: 03.10.2020
\end{abstract}

*Corresponding Author: Roez Khan

\section{Abstract}

Delay in initiation of reperfusion therapy (thrombolysis or primary Percutaneous Coronary Intervention) has been shown to be the detrimental factor of worsened outcome from ST elevated acute myocardia infarction. The data on the actual delay in initiation of reperfusion therapy in India is sparse. This study was designed to assess the various factors responsible for the delays in starting reperfusion therapy in patients presenting with ST elevated acute myocardial infarction. The results of this study indicate that a large portion of the delay was prehospital delay from the onset of angina pain to patient visiting the hospital. Factors responsible for this delay, which are totally preventable, were difficulty in arranging transport, lack of patient education and late recognition of symptom or its severity. This study also noted that there was a significant delay in hospital-door to ECG and hospital-door to thrombolytic or balloon angioplasty as well. Understandably, higher literacy level in urban patients (78.6\%) played a major role in urban patients coming to hospital for treatment more than their rural counterparts.

Keywords: ST elevated myocardial infarction, reperfusion time, and preventable causes.

Copyright @ 2020: This is an open-access article distributed under the terms of the Creative Commons Attribution license which permits unrestricted use, distribution, and reproduction in any medium for non-commercial use (NonCommercial, or CC-BY-NC) provided the original author and source are credited.

\section{INTRODUCTION}

Coronary artery disease (CAD) is the most common non-communicable disease in India and ST Elevation Myocardial Infarction (STEMI) is one of its most lethal presentations [1]. Globally, the care of STEMI patients has improved with gradually declining mortality rates due to implementation of guideline recommendation including shortening delays to implementation of specific therapies [2]. Delay in initiation of reperfusion therapy either thrombolysis or primary Percutaneous Coronary Intervention (PCI) has been shown to be clearly an important determinant of worsened outcome [3]. The data on the actual delay in initiation of reperfusion therapy in India is sparse. Systems of care for STEMI patients are also not very well developed as compared to international standards [1]. This prospective study was designed to determine the time delays at various levels of patient care that is responsible for delay in treatment of STEMI patient from onset of symptom to reperfusion in our region. We hope that the result of this study may help improve the systems of STEMI care in different parts of India as well as other regions of the developing world.

\section{MATERIAL \& METHODS}

After obtaining clearance from Institutional Ethics Committee, we recruited total 56 consecutive patients who had been admitted to J.N. Medical College with acute STEMI between $1^{\text {st }}$ August to $30^{\text {th }}$ September 2019.

\section{The Inclusion and Exclusion criteria were Inclusion Criteria}

a. Patients with acute STEMI.

b. Symptom onset outside hospital.

c. Age $\geq 18$ yrs who gave written informed consent for participation in the study.

\section{Exclusion Criteria}

d. Patients presenting after 24 hours of onset of angina.

e. Patients who did not undergo any reperfusion therapy.

f. Patients with mechanical complications requiring urgent surgery.

g. Patients whose complete medical records were not available. 
The Primary Objective of this study was to quantify the time delay from symptom onset to the institution of specific reperfusion therapies (Thrombolysis or Primary PCI) in patients of STEMI admitted at J. N. Medical College.

The Secondary objectives included identification of the various components of the time delays (symptom onset to first medical contact, first medical contact to needle/balloon times.) and to determine the various factors responsible for treatment delays in current clinical practice.

To achieve primary and secondary objectives, detailed history were taken from the patients and their relatives regarding the symptoms pertaining to the index event and the following information were obtained:

a. Demographic parameters of the patients.
b. Patient's educational status.
c. Date and time of onset of angina.
d. Time of reaching J.N. Medical College
emergency \& reasons for the delay.
e. Time of admission to Coronary Care Unit
(CCU).
f. Time taken from admission to hospital to
ECG.
g. Time of start of thrombolysis or successful
performance of primary PCI (restoration of
coronary flow).
h. History of pre-existing cardiac or other illnesses.

Any recurrent episodes of $\mathrm{MI}$ in a single patient were considered as separate events and were analyzed as such.
Overall symptom onset to reperfusion therapy time was calculated and expressed as mean, SD and median with percentiles in tables. All qualitative variables were statistically analyzed with chi-square or Fischer test wherever applicable. $\mathrm{P}<0.05$ was considered significant.

\section{RESULTS}

We recruited total of 56 consecutive patients presenting between $1^{\text {st }}$ August to $30^{\text {th }}$ September 2019 with STEMI presenting to J.N. Medical College emergency department. All these patients had reliable complete history and other relevant medical records fulfilling the inclusion and exclusion criteria mentioned in the methodology. Out of these 56 patients, 42 patients received thrombolysis as their reperfusion therapy and 14 patients had Primary PCI as their reperfusion therapy.

Table 1 shows the baseline characteristics of patients presenting with acute myocardial infarction and patients who underwent any form of reperfusion therapy. Majority of the patients were literate males. Diabetes, hypertension and smoking were co-morbid conditions associated with these patients in up to $41 \%$ patients.

Table 2 is showing the delays associated with treatment at various levels. As can be seen in the group of patients presenting to our J.N. Medical college, prehospital delays were significant with median prehospital delay of $5.6 \mathrm{~h}$ and a major portion of this delay was patient decision delay with a median of about $4.1 \mathrm{~h}$. Transportation delays were also substantial with median of $90 \mathrm{~min}$. Proportion of patients reaching to the hospital within 6 h of onset of angina was $48 \%$.

\section{STATISTICAL ANALYSIS}

Table-1: Baseline characteristics of patients presenting with myocardial infarction

\begin{tabular}{|l|l|c|}
\hline Variable & Mean \pm SD or Number (\%) & P value \\
\hline Age (Yr) & $42.6 \pm 10.2$ & \\
\hline Males : Females & $42(75): 14(25)$ & $\mathrm{P}=0.001$ \\
\hline Urban : Rural & $36(64.3): 20(35.7)$ & $\mathrm{P}=0.01$ \\
\hline Illiterates : Literate & $12(21.4): 44(78.6)$ & $\mathrm{P}=0.001$ \\
\hline Diabetes & $20(35.7)$ & \\
\hline Hypertension & $23(41.0)$ & \\
\hline Smoking & $21(37.5)$ & \\
\hline Past H/o CAD & $7(12.5)$ & \\
\hline Reperfusion therapy done at FMC center & $34(60.7)$ & \\
\hline
\end{tabular}


Table-2: Time delays at various levels of patient care

\begin{tabular}{|l|l|}
\hline Variable & Median \\
\hline Patient's Decision Delay & $250 \mathrm{~min}$ \\
\hline Pre-Hospital Delay & $340 \mathrm{~min}$ \\
\hline Delay in decision making to visit hospital. & $140 \mathrm{~min}$ \\
\hline Transportation delay & $90 \mathrm{~min}$ \\
\hline In-hospital delay & \\
\hline Door to ECG time & $15 \mathrm{~min}$ \\
\hline ECG to Reperfusion Decision time & $130 \mathrm{~min}$ \\
\hline Door to Needle time & $170 \mathrm{~min}$ \\
\hline Door to Balloon time & $180 \mathrm{~min}$ \\
\hline Angina to ECG time & $365 \mathrm{~min}$ \\
\hline Angina to Needle time & $385 \mathrm{~min}$ \\
\hline Angina to Balloon time & $395 \mathrm{~min}$ \\
\hline
\end{tabular}

\section{DISCUSSION}

World Health Organization data suggests cardiovascular disease (CVD) causes more than 2.5 million deaths annually, and as per 2014 statistics $26 \%$ of overall mortality in India is due to CVD [4]. Outcomes of patients presenting with acute myocardial infarction is time related and numerous studies have shown the association of time from presentation to reperfusion and clinical outcomes [5]. Every minute delay after STEMI is associated with increasing mortality and morbidity [5,8]. Delay in initiation of reperfusion therapy, either thrombolysis or primary PCI, has been shown to be clearly an important determinant of worsened outcome).

American Heart Association recommends performance of ECG on first medical contact (FMC) within $10 \mathrm{~min}$. In the present study, this interval had a median time of 15 min. FMC-PCI time of less than 90 min is ideal. Fibrinolytic therapy, if chosen as the primary therapy, should be administered within $30 \mathrm{~min}$ of FMC [7]. In contrast, our study noted that the Hospital Door to Needle time or the Hospital Door to Balloon angioplasty time had a median of 170 and 180 min delay. This reflects correctable lapses in our institution. Despite decreasing system delay and in hospital delays in our hospital lately, detrimental delay in starting treatment often happens due to a significant pre hospital delays. Such pre hospital delays have been shown to be an important contributor to mortality and morbidity [9]. Several factors have been associated with such delays internationally including age and sex of patients, educational status being few of them [10]. Patients delay in visiting hospital for MI remains problematic and not very well studied in India. The findings of the present study may therefore help to fill this gap in existing knowledge.

The majority of patients in this study reported to the hospital after $6 \mathrm{~h}$ of onset of angina with significant prehospital delays. The major part of the prehospital delay was the delay secondary to patient's failure to make an early decision to visit the hospital. Similar prehospital delays have been previously documented in other studies from India $[11,12]$. This is significantly longer than pre hospital delays reported internationally averaging around 2-3 hour [11]. We did not find any association with age or gender with treatment delays in this study.

Patients of rural background who reported at our medical center constituted only $35.7 \%$ of the total patients studied. This could possibly be attributed to the poor educational background and problems of arranging transportation to the nearest hospital. In the absence of state arranged transport, our patients informed us that they had to utilize public transport at exorbitant cost to reach to the hospital. Not only arranging a transport of the patient difficult in rural areas but patient's financial status also has an important implication in prehospital delays. Many of our patients with poor finances were hesitant in coming to hospital to avoid expenditure. Also, some of them reported that they tried to arrange finances before coming to hospital that took time.

Patient education regarding CAD has important bearing on pre hospital delays as can be seen by the association of longer delays in patients without a prior diagnosis of CAD. We also noted that there was also a significant association of symptom misinterpretation, failure of symptom recognition with prehospital delays.

\section{CONCLUSION}

This study shows that the major portion of delay in the treatment of the patient is prehospital delay from onset of angina to presentation to the hospital. Similar delay has also been documented from other centers in India.

\section{REFERENCES}

1. Alexander, T., Mehta, S., Mullasari, A., \& Nallamothu, B. K. (2012). Systems of care for STelevation myocardial infarction in India. Heart, 98(1), 15-17.

2. Puymirat, E., Simon, T., Cayla, G., Cottin, Y., Elbaz, M., Coste, P., \& Labèque, J. N. (2017). Acute myocardial infarction: changes in patient 
characteristics, management, and 6-month outcomes over a period of 20 years in the FASTMI Program (French Registry of Acute STElevation or Non-ST-Elevation Myocardial Infarction) 1995 to 2015. Circulation, 136(20), 1908-1919.

3. Guerchicoff, A., Brener, S. J., Maehara, A., Witzenbichler, B., Fahy, M., Xu, K., \& Stone, G. W. (2014). Impact of delay to reperfusion on reperfusion success, infarct size, and clinical outcomes in patients with ST-segment elevation myocardial infarction: the INFUSE-AMI Trial (INFUSE-Anterior Myocardial Infarction). JACC: Cardiovascular Interventions, 7(7), 733-740.

4. WHO. (2018). Global status report on noncommunicable diseases 2010 [Internet]. WHO. [Cited 2018 Oct 15]. Available from: http://www.who.int/nmh/publications/ncd_report20 10/en/

5. McNamara, R. L., Herrin, J., Wang, Y., Curtis, J. P., Bradley, E. H., Magid, D. J., ... \& Frederick, P. (2007). Impact of delay in door-to-needle time on mortality in patients with ST-segment elevation myocardial infarction. The American journal of cardiology, 100(8), 1227-1232.

6. Rodríguez-Leor, O., Fernández-Nofrerías, E., Mauri, F., Salvatella, N., Carrillo, X., Curós, A., \& Bayes-Genis, A. (2011). Analysis of reperfusion delay in patients with acute myocardial infarction treated with primary angioplasty based on first medical contact and time of presentation. Revista Española de Cardiología (English Edition), 64(6), 476-483.

7. O'Gara, P. T., Kushner, F. G., Ascheim, D. D., Casey, D. E., Chung, M. K., De Lemos, J. A., ... \&
Granger, C. B. (2013). 2013 ACCF/AHA guideline for the management of ST-elevation myocardial infarction: a report of the American College of Cardiology Foundation/American Heart Association Task Force on Practice Guidelines. Journal of the American college of cardiology, 61(4), e78-e140.

8. Rathore, S. S., Curtis, J. P., Chen, J., Wang, Y., Nallamothu, B. K., Epstein, A. J., \& Krumholz, H. M. (2009). Association of door-to-balloon time and mortality in patients admitted to hospital with ST elevation myocardial infarction: national cohort study. Bmj, 338, b1807.

9. Wu, J. R., Moser, D. K., Riegel, B., McKinley, S., \& Doering, L. V. (2011). Impact of prehospital delay in treatment seeking on in-hospital complications after acute myocardial infarction. Journal of Cardiovascular Nursing, 26(3), 184-193.

10. Taghaddosi, M., Dianati, M., Bidgoli, J. F. G., \& Bahonaran, J. (2010). Delay and its related factors in seeking treatment in patients with acute myocardial infarction. ARYA atherosclerosis, 6(1), 35.

11. George, L., Ramamoorthy, L., Satheesh, S., Saya, R. P., \& Subrahmanyam, D. K. S. (2017). Prehospital delay and time to reperfusion therapy in ST elevation myocardial infarction. Journal of emergencies, trauma, and shock, 10(2), 64.

12. Mahendran, S. (2001). Pre-hospital delay in acute myocardial infarction in an urban Indian hospital: a prospective study. The National medical journal of India, 14(1). 